\title{
RELATIVE CLAUSES IN CANTONESE-ENGLISH BILINGUAL CHILDREN
}

\section{Typological Challenges and Processing Motivations}

\author{
Virginia Yip \\ Chinese University of Hong Kong
}

Stephen Matthews

University of Hong Kong

\begin{abstract}
Findings from a longitudinal study of bilingual children acquiring Cantonese and English pose a challenge to the noun phrase accessibility hierarchy (NPAH; Keenan \& Comrie, 1977), which predicts that object relatives should not be acquired before subject relatives. In the children's Cantonese, object relatives emerged earlier than or simultaneously with subject relatives, and in their English, prenominal relatives based on Cantonese emerged first, with object relatives followed by subject relatives. These findings are discussed in light of findings on the typology and acquisition of relative clauses (RCs) and the underlying processing motivations of the NPAH. Prenominal object relatives in the bilingual children's Cantonese and English have the same word order as main clauses and can be analyzed as inter-
\end{abstract}

We thank Yasuhiro Shirai for organizing the workshop on second language acquisition of RCs at Cornell University in January 2006, where this paper was presented, as well as for his valuable comments on earlier versions of this paper. We thank all the participants at the workshop and two anonymous SSLA reviewers for their comments. Additional feedback offered by William O'Grady, Salikoko Mufwene, and John Whitman is greatly appreciated and hereby acknowledged. We thank our children for their contributions to this paper and all of the members of our research team who have contributed to this work-in particular, Uta Lam for her technical assistance. This research has been fully supported by the Research Grants Council of the Hong Kong Special Administrative Region, China (project Nos. HKU336/94H, CUHK4002/97H, CUHK4014/02H, and CUHK 4692/05H) and direct grants from the Chinese University of Hong Kong (01/02, 03/04).

Address correspondence to: Virginia Yip, Department of Linguistics and Modern Languages, Chinese University of Hong Kong, Shatin, New Territories, Kowloon, Hong Kong; e-mail: vcymatthews@cuhk.edu.hk. 
nally headed RCs. The reconceptualization of RCs as attributive clauses (Comrie, 1998a, 1998b, 2002) is supported by children's early RCs lacking a strict grammatical relationship between the head noun and the predicate. Furthermore, as observed by Diessel and Tomasello $(2000,2005)$ for English, bilingual children's earliest RCs consist of isolated noun phrases (NPS). The early object relatives produced by bilingual children are therefore essentially NPs with the linear order of a main clause, resulting in a configuration that is conducive to early production.

In this study, we discuss a putative language universal, the noun phrase accessibility hierarchy (NPAH; Keenan \& Comrie, 1977), its underlying motivation in language processing, and its predictions for the development of relative clauses (RCs) in Cantonese-English bilingual children. The NPAH has been tested in SLA largely with English and various European languages in which postnominal relatives are the norm and subject relatives consistently prove to be acquired earlier and with greater ease than object relatives. Some studies have suggested that the situation might differ when the target language has prenominal relatives, as in East Asian languages such as Japanese and Mandarin Chinese. For example, Tarallo and Myhill (1983) found that resumptive pronouns (RPs) in the subject (SU) position were judged more acceptable than those in object position by English-speaking learners of Japanese and Chinese as a second language (L2), contrary to the generalization that RPs are favored on lower positions of the hierarchy, such as direct object (DO) and indirect object (IO).

Cantonese also has prenominal RCs, although with significant differences from Mandarin (Matthews \& Yip, 2001). Matthews and Yip (2002), in their study on the development of RCs in two Cantonese-English bilingual children, reported two main findings: (a) Cantonese-based prenominal relatives were transferred to English in two bilingual children and (b) the earliest relatives recorded in both Cantonese and English were object relatives, with the head noun playing the role of object within the RC. Parallel Cantonese and English examples are given in (1) and (2), respectively. ${ }^{1}$

(1) [NP Santa Claus bei2 lei5 go3 coeng1] le1? ${ }^{2}$ (Timmy 2;08;25)

Santa Claus give you CL gun SFP

"Where's the gun Santa Claus gave me?"

(2) Where's [NP the Santa Claus give me the gun]? (Timmy 2;07;05)

[i.e., "Where's the gun Santa Claus gave me?"]

The early emergence of object relatives is not predicted by the NPAH, which states that the accessibility of a noun phrase (NP) to relativization can be captured by the following hierarchy, where > means "more accessible than": 
$\mathrm{SU}>\mathrm{DO}>\mathrm{IO}>$ oblique $(\mathrm{OBL})>$ genitive $(\mathrm{GEN})$

$>$ object of comparison (OComp)

A language that can form RCs on a given position in the hierarchy will also allow the formation of RCs on all higher positions in the hierarchy. For example, a language that can relativize oblique objects is also predicted to allow relativization on all positions to the left of OBL in the hierarchy (i.e., SU, DO, and IO).

Before we move on to the predictions of the NPAH for our bilingual acquisition study, it is necessary to discuss the role of typological universals in language acquisition. Despite the prevalence of studies on applying typological universals in SLA, an important issue remains as to whether and how the learner has access to generalizations of a typological nature. ${ }^{3} \mathrm{~A}$ similar problem raised by Tomlin (1994) concerns the logic of interlanguage studies that make use of typological generalizations to provide explanations in SLA because

the individual language learner has no access to such generalizations. To the extent that such efforts represent a shorthand means of expressing more individual-specific cognitive or linguistic principles, then appropriate clarification is needed to articulate what those individual-specific general linguistic principles must be. (p. 152)

Pursuing this challenge, Yip and Matthews (1995) argued that to impute a typological generalization to a learner is to assume that they have access to whatever knowledge underlies the typological characteristics in question. In order to be explanatory, typological universals must be expressed in terms that can be attributed to the learner's competence. For example, the linguistic knowledge in question might be encoded in Universal Grammar (UG) or in the learner's first language (L1). Another alternative is to derive the relevant grammatical properties from processing principles that are independent of UG. The NPAH itself has never been attributed to UG; rather, it has been argued to reflect processing factors (Hawkins, 1994, 2004) and, specifically, "the increasing complexity of the processing domains for different relativizable positions" (Hawkins, 2004, p. 177). Implicit in much of the research is the assumption that these processing factors are applicable to children-monolingual or bilingual-as well as to adults.

The predictions of the NPAH for language acquisition are spelled out by J. Hawkins (1987, this issue). An implicational universal of the form "if P then Q" does not strictly predict that $Q$ must be acquired before $P$; rather, it predicts that $Q$ will be acquired either earlier than or simultaneously with $P$. What is ruled out is a language in which $\mathrm{P}$ holds but not $\mathrm{Q}$; developmentally, this means acquiring $\mathrm{P}$ before $\mathrm{Q}$ (e.g., object relativization before subject relativization).

Matthews and Yip's (2002) finding that Cantonese-English bilingual children produced object relatives before subject relatives implies a developmental stage ruled out by the predictions of the NPAH. In this study, we reconsider the challenge posed to the NPAH by the data in light of recent developments in the study of typology and child language acquisition. We also provide addi- 
tional data from a third bilingual child that confirm and add to the overall picture of development instantiated in the two older siblings.

\section{TYPOLOGICAL BACKGROUND}

To set the stage for the analysis of RC development in the bilingual children, we outline three typological characteristics of RCs in East Asian languages as instantiated in Cantonese: (a) the prenominal position of RCs, (b) the existence of attributive clauses, and (c) the possibility of head-internal RCs.

\section{Prenominal RCs}

Studies in constituent order typology have demonstrated a striking asymmetry in the distribution of prenominal and postnominal RCs. Based on head direction, one would expect head-final languages to have prenominal RCs. In fact, however, even OV languages show a slight preference for postnominal relatives over prenominal relatives, whereas in VO languages, postnominal relatives are ubiquitous and prenominal relatives are clearly attested only in Chinese (Hawkins, 1990). In Dryer's (1992) language sample, 98\% of VO languages and $58 \%$ of $\mathrm{OV}$ languages had postnominal relatives, whereas Chinese languages provided the only clear examples of the rare combination of VO order and prenominal relatives. The overall preference for postnominal relatives might be attributed to processing problems that arise with prenominal but not postnominal relatives, such as center-embedding and online ambiguities. The extreme rarity of the combination of word-order properties found in Chinese (VO and RC before noun) is also attributable to additional processing considerations that disfavor it (Hawkins, 1994). The combination of VO order with prenominal relatives creates configurations as in (3), illustrated by a hypothetical English-based example in (4):

(3) $[\mathrm{vP} V[\mathrm{NP}[\mathrm{s} R \mathrm{RC}] \mathrm{N}]$

(4) I [vp ate [NP [s you bought yesterday] the cakes.]

With the RC "you bought yesterday" intervening between the verb "ate" and its object "the cakes," this configuration incurs an indefinitely long delay in the parsing of the object NP, and hence also of the verb phrase (VP), while the parser awaits the head noun. This delay can be measured using the notion of constituent recognition domain (CRD) proposed by Hawkins (1994): "The CRD for a phrasal mother node $M$ consists of the set of terminal and nonterminal nodes that must be parsed in order to recognize $\mathrm{M}$ and all ICs [immediate constituents] of M" (p. 58). In (3), VP is a mother node M, dominating the immediate constituents $\mathrm{V}$ and NP. In order for the second constituent (NP) to be recognized, an unambiguous cue to construct a NP is required; we assume 
this to entail that the head noun itself must be parsed. ${ }^{4}$ The CRD for VP then extends from $\mathrm{V}$ through the $\mathrm{RC}$ to the head $\mathrm{N}$, as in (5):

(5) $\quad[\mathrm{vP} V[\mathrm{NP}[\mathrm{s} R \mathrm{RC}] \mathrm{N}]$

Constituent recognition domain for VP

The longer the $\mathrm{RC}$, the longer the $\mathrm{CRD}$ becomes and the lower the parsing efficiency achieved by the configuration; some experimental evidence for this is provided by Matthews and Yeung (2001).

\section{Cantonese Relatives as Attributive Clauses}

A second typological feature of many East Asian languages is that it often proves difficult or impossible to separate RCs from other prenominal modifiers. Comrie (1996, 1998a, 1998b, 2002) proposed that these languages have attributive clauses of which RCs are merely a subset or, at best, a special case. This entails that RCs in the East Asian languages concerned are qualitatively different from those in European languages. First, these languages allow the attributive modifier to be a clause in which the head noun does not need to take a grammatical role. Instead, the modifying clause can be more loosely associated with the head noun based on semantic and pragmatic links. For example, in Cantonese:

(6) $[\mathrm{NP}[\mathrm{s}$ Lei5 waat6-syut3] go2 di1 soeng2]

you slide-snow DEM CL pictures

"The pictures of you skiing; your skiing pictures"

There is no grammatical relation at all between soeng2 "pictures" and waat6syut3 "ski"; rather, the pictures are associated pragmatically with skiing. There is substantial evidence that the children's developing grammar allows modifying clauses that involve no grammatical relationship between the head and the RC:

(7) $[\mathrm{NP}[\mathrm{s}$ zong6 ce1] go2 go3] (Alicia 1;10;16, corpus data)

crash car DEM CL

"the one with the car crash"

Without context, this utterance appears to be a subject relative "the one that crashed the car." The context shows, however, that the child is referring to a picture in the newspaper showing an accident involving a car crash. The pronominal head go2 go3 "that one" does not refer to the subject of zong6 ce1 "crash car," and the structure is not a subject relative but an attributive clause with no specified subject. Alicia also produced similar examples of this construction in English, as in (8): 
(8) Oh, [NP so many [s eat] something]. (Alicia 2;10;04)

[i.e., so many things for eating!]

A second, more controversial hypothesis in Comrie's (1998a) proposal for Japanese is that attributive clauses involve no extraction and there is no fillergap dependency. In the case of attributive clauses such as (6), in which the head noun has no grammatical relation in the modifying clause, there is clearly no gap and no filler-gap dependency arises. Where a grammatical relation can be identified, Comrie still argued that no gap or filler-gap dependency need be assumed because Japanese rather freely allows null anaphora. ${ }^{5}$ Under the conventional analysis of a typical object relative as a head-final RC, there would be a gap following the verb, as shown in (9):

(9) [NP $[$ s Po4po2 maai5 _ $]$ di1 tong4-tong2] ne1? (Timmy 2;07;12)
grandma buy CL candy-candy SFP
"What about the candies Grandma bought?"

Comrie's insight that a gap need not be assumed in this type of object relatives can also be implemented in another way: under the internally headed $\mathrm{RC}$ analysis outlined in the next section. There is no need to assume a gap because the structure is essentially that of a SVO main clause, with the object in situ (see also Jeon \& Kim, this issue).

\section{Prenominal Object Relatives as Internally Headed RCs}

A third insight that derives from language typology is that children's early prenominal object relatives might be internally headed RCs. Although Chinese is generally assumed to have only head-final RCs, a number of East Asian languages, including Korean and Japanese, have both head-final relatives and head-internal RCs (IHRCs) - that is, constituents that have the syntax of a clause internally, but that of a NP externally (cf. Keenan, 1985). A typical IHRC in Korean (Jeon \& Kim, this issue) retains the SOV order of a main clause as in (10):
John-un $[\mathrm{NP}[\mathrm{s}$
John-TOP
chayk-(ul) pilli-n]
kes]-ul
toli-e cwu-ess-ta
"John returned the book he borrowed."

Here, the relativized head noun chayk "book" appears as the object of an OV clause and is therefore internal to the clause. In terms of online parsing, the clause resembles a SOV main clause until the point where it is marked by the adnominal verbal suffix $-n$ and the nominalizer or complementizer kes at its right boundary. Developmentally, both children and adult L2 learners of Korean have been shown to acquire IHRCs earlier than head-final relatives, in the sequence headless $>$ head-internal $>$ head-external (Jeon \& Kim, this issue). 
The authors attribute this sequence to syntactic complexity: The head-internal relative does not involve the extraction of the lexical head but only the addition of verb inflection and of the complementizer kes. According to Jeon and Kim, the IHRC favors object relatives, as in (10), over subject relatives.

In both child and adult Cantonese, a subset of object RCs can be analyzed as IHRCs. The RCs concerned are classifier relatives that contain a demonstrative and classifier but no relative marker comparable to de in Mandarin Chinese (Matthews \& Yip, 2001). Under the head-internal analysis, the RC in (11) has the internal structure of a SVO clause but, in terms of its external syntax, it behaves as a NP, functioning as the subject of the main clause ${ }^{6}$ :

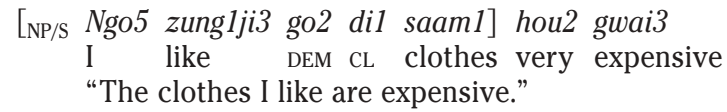

We represent the IHRC analysis by the notation NP/S, indicating a constituent that externally has the syntax of a NP but internally that of a clause (S). When this type of analysis is applied to adult Cantonese, a number of problems arise: Whereas the simplest type of object relative in (11) resembles a main clause, evidence from a number of more complex transitive constructions shows that main clause and RC structures are not entirely parallel (Matthews \& Yip, 2001, 2002). Thus, the analysis of classifier relatives as internally headed RCs as shown in (11) might not be applicable to adult Cantonese as a whole. Such an analysis remains possible, however, in the case of object relatives with simple transitive verbs such as (9), which are precisely the structures that are predominant in the child data. Thus, the IHRC analysis for (9) would be as in (12):

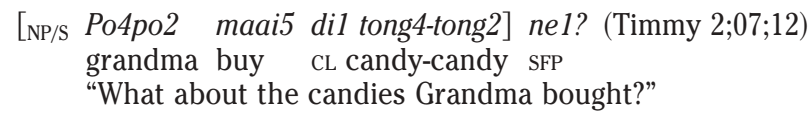

To summarize, RCs in Cantonese are consistently prenominal, consistent with a head-final analysis. However, a subset of object relatives can also be analyzed as head-internal RCs, and there is evidence that suggests that they are to be analyzed accordingly in children's early Cantonese. We return to this possibility in the discussion that follows.

\section{DATA FOR THIS STUDY}

The data for this study come from a series of projects that investigated grammatical development in Hong Kong Cantonese-English bilingual children between the ages of 1;03 and 4;06. A total of six children's longitudinal datasets are available in the Hong Kong Bilingual Child Language Corpus and have 
been deposited in the CHILDES archive (MacWhinney, 2000). ${ }^{7}$ The children were exposed to both Cantonese and English from birth and their parents adhered to the one parent-one language strategy in addressing the children. The corpus is based on weekly or biweekly recordings of half an hour for each language, during which the child interacted with two research assistants (each speaking a different language) in their daily activities and sometimes with the parents, siblings, and other caretakers present.

\section{Diary Data}

Although six bilingual children's corpus data are currently available, the data in this article are primarily diary data from the authors' own three bilingual children (Timmy, Sophie, and Alicia) with a few examples from the corpus data (which will be specified). The availability of diary data for these three siblings enables us to address the development of RCs, which appear rarely, if at all, in the longitudinal corpus data. The age ranges during which diaries were kept was 1;03-6;00 for Timmy, 1;06-5;06 for Sophie, and 1;00-5;04 for Alicia. The diaries include several entries per week and were intended to complement the video and audio recordings. Both parents were involved in recording the diary data in the two languages, although the coverage of English data was more extensive than for Cantonese. The contexts mostly involved interactions between the child and parents at home or occasionally away from home. Relevant contextual information was given as much as possible in the diary entries. We believe that the diary data are reliable to the extent that they are systematic: The major patterns described here are instantiated at least three times. Such recurrent patterns imply developing competence rather than performance alone. The representativeness of the diary data presents a more serious problem: Inevitably, there is selection bias, whereby unusual and nonnativelike utterances were more likely to be recorded than unremarkable and well-formed ones. For this reason, we use the diary data essentially for qualitative analysis, not as the basis for any quantitive claims. For example, recurrent diary entries allow us to make the generalization that nontargetlike structures such as prenominal RCs are used productively; they do not allow us to quantify the frequency of such structures relative to monolingual children.

An important point is that the development of RCs in the three siblings' English can be seen to be following a similar course independently. The eldest child, Timmy, produced prenominal relatives in his English from 2;07 to 4;0, at which point the second child was aged 1;03. Similarly, Sophie ceased to use prenominal relatives at age 5, when her sister Alicia was only 7 months old. Given this chronology, it is unlikely that nonnative input containing prenominal relatives is a factor in the younger children's production of these structures. ${ }^{8}$ Rather, the dominance of Cantonese leads to similar patterns of transfer in each of the three bilingual children. 


\section{Language Dominance}

Where the quantity of input available to bilingual children is uneven, one of the languages tends to develop faster and become the dominant language (Döpke, 1998; Genesee, Nicoladis, \& Paradis, 1995). Our three siblings show similar patterns of development: All three show evidence of dominance of Cantonese, as measured by mean length of utterance (MLU) in the two languages, language preference, and other indicators (see Yip \& Matthews, 2000, 2006, 2007). This pattern, in turn, is attributed to an imbalance of input: In the extended family environment, many relatives speak Cantonese to the children, whereas English input comes only from the father and a domestic helper from the Philippines. Reflecting this pattern of dominance, the children's English shows transfer from Cantonese in several domains, including wh-insitu and null objects as well as RCs (Yip \& Matthews, 2000). Influence in the other direction, from English to the children's Cantonese, is difficult to detect at all and appears only in certain vulnerable domains such as prepositional phrases and dative constructions-areas in which developmental difficulties are observed even in monolingual children (Yip \& Matthews, 2007).

Yip and Matthews (2006) proposed the MLU differential, as defined in (13), as a measure of language dominance.

(13) The MLU differential is the difference between MLU scores for a child's two languages at a given sampling point or (expressed as a mean) over a period of development.

We consider the MLU differential between the bilingual child's two languages to be one of the most objective measures of language dominance. ${ }^{9}$ The mean MLU values and the MLU differentials of the three siblings are given in Table 1. MLU is measured by dividing the total number of morphemes or words by the number of utterances. The MLU reported in this study was calculated in terms of words rather than morphemes. Issues involving the calculation of MLU in words versus MLU in morphemes in child Cantonese and English were discussed by Yip and Matthews (2006), who treated both languages as predomi-

Table 1. Mean MLU and MLU differentials in three siblings

\begin{tabular}{lccc}
\hline MLU & $\begin{array}{c}\text { Timmy }^{\mathrm{a}} \\
(2 ; 01 ; 22-3 ; 06 ; 25)\end{array}$ & $\begin{array}{c}\text { Sophie }^{\mathrm{b}} \\
(1 ; 06 ; 00-3 ; 00 ; 09)\end{array}$ & $\begin{array}{c}\text { Alicia }^{\mathrm{b}} \\
(1 ; 03 ; 10-3 ; 00 ; 24)\end{array}$ \\
\hline Cantonese & 3.51 & 2.58 & 2.50 \\
English & 3.12 & 1.73 & 1.71 \\
Differential & 0.39 & 0.85 & 0.79 \\
\hline
\end{tabular}

aTwenty-five files per language.

bForty files per language. 
nantly isolating languages, especially because inflectional morphology was not yet in place in the children's English. In an ideal isolating language, by definition, each morpheme can be considered a separate word, thus neutralizing the differences between morpheme and word measures. Timmy's mean MLU (Cantonese 3.51, English 3.12) was derived by averaging the MLU of 25 transcription files per language from 2;01;22 to 3;06;25, whereas Sophie's mean MLU (Cantonese 2.58, English 1.73) is the average of the MLU of 40 transcription files per language from 1;06 to 3;00;09, and Alicia's mean MLU (Cantonese 2.50, English 1.71) is the average of 40 files per language from $1 ; 03 ; 10$ to $3 ; 00 ; 24$.

Based on the MLU differentials shown in Table 1, it appears that Sophie and Alicia (with mean MLU differentials of 0.85 and 0.79 , respectively) were more strongly and consistently Cantonese-dominant over the period of study than Timmy, who showed a differential of 0.39. Over the whole period of study, the mean Cantonese MLU values for Sophie and Alicia were nearly one MLU point above those for English. Thus, the dominance of Cantonese as indicated by the MLU differential and time of the child's first utterance in Cantonese and English is clearer in the cases of Sophie and Alicia than in the case of Timmy. Overall, the three siblings can be considered dominant in Cantonese in the first few years of their bilingual development. Moreover, there is relatively little evidence of transfer from English to Cantonese in these children except in certain vulnerable domains (Yip \& Matthews, 2007) and none in the domain of RCs-in particular, we did not find postnominal relatives in the children's Cantonese. Together, these findings implicate the dominance of Cantonese as a causal factor that favors transfer from Cantonese to English.

As Paradis and Genesee (1996) noted:

Transfer is most likely to occur if the child has reached a more advanced level of syntactic complexity in one language than the other. Such a discrepancy could occur either because it is typical in the monolingual acquisition of the two languages, or because the child is more dominant in one of his or her languages. (p. 3)

The two alternative explanations for transfer noted by Paradis and Genesee, which we term developmental asynchrony and dominance, respectively, are discussed in depth in Matthews and Yip (2002) and Yip and Matthews (2007). Under either view, the child has knowledge in one language (Cantonese, in this case) that he or she lacks in the other and transfers this knowledge as an interim strategy.

\section{DEVELOPMENT OF RCs IN BILINGUAL CHILDREN}

All three siblings showed two distinct stages in the development of RCs in English. In the first stage, the prenominal RC was transferred from Cantonese, whereas in the second stage, postnominal relatives emerged, initially with RPs and, subsequently, as target structures without them. Table 2 shows the age 
Table 2. Age of first emergence of subject and object RCs in Cantonese and English in three bilingual children

\begin{tabular}{|c|c|c|c|c|c|c|}
\hline \multirow[b]{2}{*}{ RC type } & \multicolumn{3}{|c|}{ Cantonese $^{\mathrm{a}}$} & \multicolumn{3}{|c|}{ English } \\
\hline & Timmy & Sophie & Alicia & Timmy & Sophie & Alicia \\
\hline \multicolumn{7}{|l|}{ Prenominal } \\
\hline Subject & $2 ; 04 ; 28$ & - & $4 ; 08 ; 13$ & - & $3 ; 10 ; 09$ & $3 ; 08 ; 01$ \\
\hline Object & $2 ; 04 ; 28$ & $2 ; 09 ; 05$ & $2 ; 01 ; 01$ & $2 ; 07 ; 03$ & $3 ; 03 ; 12$ & $3 ; 05 ; 06$ \\
\hline \multicolumn{7}{|c|}{ Postnominal } \\
\hline Subject & $\mathrm{n} / \mathrm{a}$ & $\mathrm{n} / \mathrm{a}$ & $\mathrm{n} / \mathrm{a}$ & $3 ; 10 ; 23$ & $5 ; 04 ; 19$ & $4 ; 05 ; 03$ \\
\hline Object & $\mathrm{n} / \mathrm{a}$ & $\mathrm{n} / \mathrm{a}$ & $\mathrm{n} / \mathrm{a}$ & $3 ; 04 ; 07$ & $4 ; 10 ; 28$ & $5 ; 02 ; 17$ \\
\hline
\end{tabular}

${ }^{a}$ Clauses with relative marker ge 3 and those formed with a demonstrative and classifier immediately preceding the noun.

of first emergence of RCs based on the three bilingual children's combined corpus and diary data. In the case of the diary data, these dates were obtained by manual searching. The longitudinal corpora were initially searched by extracting utterances containing the demonstrative go 2 or the morpheme ge 3 in Cantonese and that in English (wh-relatives are lacking, for reasons discussed in Matthews \& Yip, 2002), followed by manual identification of possible RCs in context. Because these are naturalistic data and the structures are relatively infrequent, the first attestations are likely to lag behind the initial use of each type. Moreover, in two cells in Table 2, subject relatives are not attested at all.

In Cantonese, object relatives emerged at about the same time as subject relatives, as for Timmy (at 2;04;28), or earlier than subject relatives, as for Sophie (at 2;09;05) and Alicia (at 2;01;01). Cantonese subject relatives were not attested in Sophie's corpus or diary data; in Alicia's diary data, the first clear example of a subject relative was recorded as late as 4;08;13, although we assume that this structure emerged earlier, if only because Alicia transferred it to English from 3;08 onward.

In English, prenominal object relatives emerged earlier than subject relatives in Sophie's data (3;03;12 vs. $3 ; 10 ; 09)$ and Alicia's data (3;05;06 vs. 3;08;01), although in the case of Timmy, prenominal object relatives emerged as early as 2;07;03 and prenominal subject relatives were not attested. With regard to English postnominal relatives, object relatives preceded subject relatives for Timmy $(3 ; 04 ; 07$ vs. $3 ; 10 ; 23)$ and Sophie $(4 ; 10 ; 28$ vs. $5 ; 04 ; 19)$, whereas subject relatives preceded object relatives for Alicia (4;05;03 vs. 5;02;17).

To summarize, the ages of first emergence of RCs in Table 2 pose some challenges to the NPAH:

1. In the bilingual children's Cantonese, object relatives emerged earlier than or simultaneously with subject relatives.

2. In the bilingual children's English, Cantonese-based prenominal relatives emerged first, with object relatives followed by subject relatives. 
3. When targetlike postnominal relatives emerged in the bilingual children's English, object relatives preceded subject relatives for two of the three children.

All of these findings run counter to the predictions of the NPAH.

\section{Transfer of Cantonese-Based Prenominal Relatives}

Based on diary data, prenominal object RCs emerged in Timmy's Cantonese and English during the same week: ${ }^{10}$

(14) $[\mathrm{NP}[\mathrm{s}$ Jan maai5] go2 tiu4] (Timmy 2;07;04)

Jan buy DEM CL

"The one that Jan bought" [i.e., a pair of trousers]

(15) Where's [NP [s you buy] that one],

where's [NP [s you buy] that one the motorbike] (Timmy 2;07;03)

[i.e., "where's the one you bought?" "where's the motorbike you bought?"]

The Cantonese example in (14) is a headless RC, with a classifier but no head noun; in (15), Timmy reproduced essentially the same structure in English with "one" and then with "the motorbike" as the head.

Prenominal RCs appeared substantially later in Sophie's English, at around age 3;03. (This relative delay is expected because Sophie's Cantonese production ability was well ahead of her English at this period; she began to produce sentences in Cantonese at 11 months and in English only at around age 2.) Between ages 3;03 and 4;03, Sophie produced only relatives headed by "one," without a lexical head noun:

(16) Child: [NP Timmy take that one], I want.

Father: Which one do you want?

Child: [NP She take that one]. [NP Timmy take that one]. (Sophie 3;03;12)

(17) Child: I also want.

Father: What do you want?

Child: [NP Timmy said that one]. (Sophie 3;08;21)

(the child has been asking for a piggy-bank)

(18) $\quad[\mathrm{NP}$ I buy in the store that one] is yummy. (Sophie 4;03;17)

(Talking to her brother about lemon sweets)

With "one" serving as the head, these examples are based on the headless Cantonese construction with demonstrative and classifier but no head noun, as illustrated by Timmy in (14). Whereas Timmy expanded the structure with "one" into a full-fledged RC by adding a head noun, as in (15), Sophie replaced "one" with a head noun, as seen in (19):

(19) Father: Which dress?

Child: The. . . [NP you take for me that one]. . .Where is it, [NP you said it that dress]? (Sophie $4 ; 04 ; 20$ )

The two RCs used to specify the same dress are revealing; the first has the pronominal "one" as the head, whereas the second has "that dress" as the 
head noun as well as a RP "it" (the only clear case of a RP in a prenominal RC in our data). The context confirms that "you said it that dress" means "the dress you mentioned," as the father had recommended a certain dress to go with her gloves and shoes.

All of the examples listed previously are object relatives, attested from age 3;03 onward. The earliest potential subject relative is recorded some 7 months later:

(20) I want [NP [s have ear-ear] that one]. (Sophie 3;10;09)

"wanting to wear a coat that has ears"

Whereas this can be taken as a subject relative ("the one that has ears"), it can also be interpreted as an attributive clause ("the one with the ears on it") without a true grammatical relation between the head noun and the modifying clause.

Like Sophie, Alicia began by producing RCs with "one," first with object relatives, as in (21), and 3 months later with putative subject relatives, as in (22), parallel to Sophie's (20):

(21) Daddy, where is that blue bag? [NP My. . . me make that one]? (Alicia 3;05;06)

[i.e., "the one I made"]

(22) Father: What shall we put on you?

Child: [NP Have gung1zai2 that one]. (Alicia 3;08;01)

[i.e., "The dress that has cartoon characters on it"]

Alicia had already acquired the equivalent object relative construction in Cantonese around 2;01, as seen in (23), where a classifier serves as the head in the absence of a head noun:

(23) Ngo5 waak6 go2 go3 le1?

I draw DEM CL SFP

"Where's the one I drew?" (Alicia 2;01;01)

Alicia's development thus replicated that of her siblings, with object relatives emerging first in Cantonese, as in (23), and then being transferred to English, as in (21) and (22). Being 4 years and 3 months younger than Sophie, the possibility of Alicia acquiring the English structure directly from her siblings is even less likely than in the case of Sophie's development. Thus, we have every reason to assume that Alicia's prenominal relatives in English developed independently, without modeling her older siblings' speech.

\section{Emergence of Postnominal Relatives in English}

The transition from prenominal to postnominal relatives is described in detail by Matthews and Yip (2002). Of particular relevance to the NPAH is the occurrence of RPs. Both in typology and SLA, RPs are more likely to appear in the 
lower positions of the hierarchy. A reverse implicational hierarchy might be established for RPs: If RPs are allowed in a given position on the NPAH, they will be allowed in all lower positions. Among several SLA studies, Gass and Ard (1984) found evidence that RPs are "most likely in OComp relatives and least likely in subject relatives" (p. 47), which was true for all participants in their study, illustrating the inverse relationship of RPs and their positions on the hierarchy (see also Hyltenstam, 1984).

The first examples of this type in Timmy's data were recorded at 3;04 with $\mathrm{RP}$ in the object position, in (24), and occasionally in subject position, as in (25):

(24) It's like the one you bought it. (seeing picture of toy car)

It's not like the one you bought it. (seeing difference) (Timmy 3;04;07)

(25) Daddy, where's the thing? Where is the thing it hangs? The one it says one for me, one for Sophie? [looking for coat-hangers with the children's names painted on them] (Timmy 3;10;23)

In Sophie's English, RPs were also observed in the object position when postnominal relatives first appeared, shortly before age 5:

(26) I got that red flower dress that Jan give it to me. (Sophie 4;10;28)

(27) This is the homework that I do it. But, I done already at school. (Sophie 4;11;04)

When the complementizer that appeared in Sophie's data at age 4, RPs were used sporadically, for example, in sentences with the verb put, as in (28).

(28) I want the sweet, the sweet that you put it there yesterday. (Timmy 4;00;03)

As we have seen, Sophie began to produce postnominal relatives shortly before age 5, initially with RPs in the object position, as seen in (26) and (27). One month later, similar object relatives appeared without the pronouns, as in (29) and (30).

(29) Thank you for the dress that you give to me, for the dolly. (Sophie 5;00;04)

(30) Hey, this is the clips that Belma buy. (Sophie 5;00;05)

Resumptive pronouns continued to appear in more complex structures, such as object relativization within an embedded clause:

(31) Daddy, where's the fox hole, that you said you find it yesterday? (Sophie 5;04;15)

Compare a similarly complex example from Timmy, in which the RP occurred first in the object position and then in the subject position in a coordinate construction: 
(32) I need the train that you push it and it goes. (Timmy 4;03;09)

[i.e., "I want the train that goes when you push it."]

In such cases, the pronouns might be used even in adult English, as Hawkins (1999) observed: "English gaps in complex NP environments can sometimes be rescued by pronoun retention" (p. 265). In McKee, McDaniel, and Snedeker's (1998) experimental study of 28 monolingual children aged $2 ; 02-3 ; 10,80 \%$ of target RCs were produced by the children; occasional errors involved RPs, as in (33), and nontarget relative pronouns, such as what in (33) and why in (34) $)^{11}$ :

(33) Strawberries-pick those two up what the dinosaur is eating them. (CT, 2;10)

(34) Bicycle-pick this one up why Dorothy's riding. (CT, 2;10)

(McKee et al., 1998, pp. 586-587, emphasis added)

McKee et al. suggested a performance account of the RPs on the grounds of their sporadic appearance and processing demands, just as in the case of RPs in adult English. In our bilingual children's production data, however, the productive use of RPs argues for a grammar that systematically generates RPs in $\mathrm{RCs}$ at this transitional stage.

Although the appearance of RPs in object relatives is consistent with the NPAH, a remaining puzzle is that for two of the three children, postnominal object relatives appeared to be acquired earlier than subject relatives (see Table 2). It is possible that the primacy of object relatives in the prenominal position in Cantonese-dominant children somehow transferred to RCs in the postnominal position. However, with only two out of three subjects showing this pattern, this finding calls for further research and experimentation.

\section{DISCUSSION}

The prenominal relatives observed in the bilingual children's English were initially object relatives rather than subject relatives. This pattern runs counter to the NPAH (Keenan \& Comrie, 1977), which would predict that a language or interlanguage allowing object relatives would allow subject relatives as well. In the following subsection we discuss three factors that might favor the development of object relatives in the bilingual acquisition of Cantonese and English.

\section{Isomorphism Between Prenominal Object Relatives and Main Clauses}

Matthews and Yip (2002) suggested that the early emergence of object relatives is facilitated by canonical word order: Given the unique combination of prenominal relatives and SVO clausal order in Cantonese, object relatives 
resemble the SVO order of a main clause. This parallelism is shown schematically in (35):

RC: $[\mathrm{NP}[\mathrm{NP} \mathrm{V}] \mathrm{N}]$

Main clause: $(\mathrm{S}) \mathrm{V}(\mathrm{O})$

If we analyze this structure conventionally as a head-final object relative, it would contain a gap in object position, which would distinguish the RC configuration from that of a main clause:

(36) RC: $\left[\mathrm{NP}\left[\mathrm{NP} \mathrm{V}_{-}\right] \mathrm{N}\right]$

Main clause: $(\overline{\mathrm{S}}) \mathrm{V}(\mathrm{O})$

There is no need to assume such a gap, however, if the RCs are analyzed either (a) as attributive clauses lacking gaps, as suggested by Comrie (1998a, 1998b), or (b) as head-internal relatives. Without a gap, the resemblance to a SVO main clause is even closer, as shown in (35). In the case of subject relatives, by contrast, there is no such parallel with main clause word order. Assuming a gap in the subject position, a subject relative would be analyzed as in (37), corresponding to VOS rather than SVO:

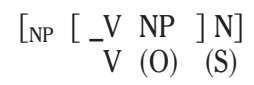

Note that these configurations apply only to languages (or interlanguages, in the case of our bilingual children) with the rare combination of prenominal relatives and SVO word order. As is well known (Bever, 1970; Tavakolian, 1981), in languages like English with postnominal relatives and SVO main clause order, the isomorphism arises with subject relatives (38), not in object relatives (39):

$$
\text { (S) } \mathrm{V}(\mathrm{O})
$$

(39) $\left[\mathrm{NP} N \quad\left[\mathrm{NP} \mathrm{V}_{-}\right]\right]$

(O) (S) $\mathrm{V}^{-}$

The prenominal relatives observed in the children's bilingual development are not known to occur in monolingual children, who uniformly produce postnominal relatives in accordance with the properties of English in the input. In both longitudinal corpus-based studies and experimental studies, the findings have converged on the ease of subject relatives over object relatives (see review by Diessel \& Tomasello, 2000, 2005). As Diessel and Tomasello (2005) suggested, this is consistent with the word order isomorphism, as shown in (38); that is, the explanation they propose for English is essentially the same as that proposed by Matthews and Yip (2002) for Cantonese, except that the Cantonese configuration in (35) favors object relatives rather than subject relatives.

The isomorphism between object relatives and main clause word order in Cantonese therefore facilitates processing of prenominal object relatives at the expense of subject relatives. Based on this isomorphism, Matthews and 
Yip (2002) predicted that object relatives in Cantonese should be (a) produced earlier than subject relatives by monolingual children and (b) processed faster, more accurately, or both faster and more accurately by both children and adults. Recent results from adult processing of relatives in Mandarin Chinese have been mixed. Using a moving-window reading task, Hsiao and Gibson (2003) found that Mandarin object relatives were indeed processed faster than subject relatives in the critical regions of the sentences examined. As the authors noted, this finding is contrary to the NPAH but consistent with Gibson's (1998) processing account as well as with the canonical word order account suggested previously. In contrast, a study by Lin, Fong, and Bever (2005) found an advantage for Mandarin subject relatives over object relatives, consistent with the NPAH. ${ }^{12}$ For monolingual Cantonese development, elicited imitation and comprehension experiments conducted by Lau (2006) also suggested a subject advantage in Cantonese, contrary to our developmental findings. One possible explanation for the conflicting findings would be an asymmetry between production and comprehension: An identical match between the RC and main clause on the surface might facilitate production but create parsing problems in comprehension due to ambiguity (Y. Shirai, personal communication, July 2006). This idea is appealing because asymmetries between production and comprehension are known to exist in various areas of language processing. More studies that examine both production and comprehension would be needed to verify and demonstrate the extent of this asymmetry.

\section{Internally Headed Analysis of Early Object Relatives}

As we noted earlier, object relatives in Cantonese can be analyzed as headinternal RCs. As early as age 2;01, Alicia produced utterances such as (40), which might be analyzed as main clauses (40a), internally headed object relatives (40b), or head-final RCs (40c):

(40) Alicia waak6 go2 di1 je5 [pointing to her own drawings] (Alicia 2;01;21)

Alicia draw DEM CL things

"[These are] the things that Alicia drew"

(40a) [s Alicia waak6 go2 di1 je5] (SVO main clause) Alicia draw DEM CL things

"Alicia drew those things"

(40b) [NP/S Alicia waak6 go2 dil je5] (IHRC) Alicia draw DEM CL things

"[These are] the things that Alicia drew"

(40c) [NP [s Alicia waak6 _ [go2 dil je5 $]]$ (head-final relative) Alicia draw DEM CL things

"[These are] the things that Alicia drew" 
The interpretation of (40) as a RC (whether internally headed or head-final) is supported by a rare example from the corpus, produced a few days earlier and presented in (41), which unambiguously involved a RC because the particle lel followed a NP (see Note 4):

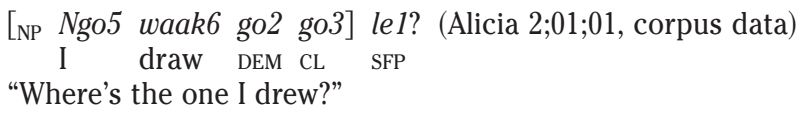

A final piece of suggestive evidence for the internally headed RC analysis involves child utterances that are not well formed in terms of adult usage but are consistent with the internally headed analysis, as in (42):

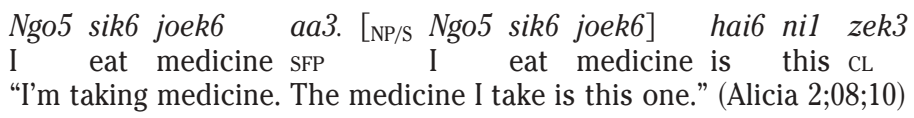

The second clause is ill-formed because either the attributive particle ge 3 or the demonstrative go2 plus classifier, as seen in (40), would be required before the head noun joek6 "medicine" for a RC interpretation. It is, however, consistent with the analysis whereby the child is using a clause [s Ngo5 sik6 joek6] "I take medicine" as an internally headed RC [NP Ngo5 sik6 joek6] "the medicine I take." In elicited imitation experiments by Lau (2006), children produced numerous utterances of this type that, like (42), were ill-formed in terms of adult grammar but consistent with the IHRC analysis. Regardless of whether this analysis accurately characterizes the child's initial grammar, the isomorphism between prenominal object relatives and main clauses would still facilitate the production of this type of object relative.

\section{Children's RCs as Isolated NPs}

Another relevant factor in accounting for the early emergence of object relatives is that the earliest RCs in child English modify isolated NPs (Diessel \& Tomasello, 2000, 2005). Isolated NPs in our data include

(43) [NP Jan4dei6 sung3 bei2 ngo5 go2 go3] aa3, people present give me DEM CL SFP

"The one someone gave me as a present,"

[NP jan4dei6 bei2 ngo5 go2 go3] aa3

people give me DEM CL SFP

"The one [candy] someone gave me." (Alicia 3;04;21)

In conjunction with the canonical word order discussed previously, this makes object relatives even easier to process because they have exactly the form of a SVO clause. ${ }^{13}$ 
Apart from isolated NPs, children's earliest relatives might be NPs introduced by a wh-phrase, a copula verb, or both:

(44) The girl that came with us (Nina 3;00; Diessel \& Tomasello, 2005, p. 883)

(45) What's dat. . you have? (Adam 2;11; Diessel \& Tomasello, 2005, p. 883) [i.e., What's that that you have?]

Again we have found similar examples among the bilingual children's prenominal relatives:

(46) Where's [the Santa Claus give me the gun]? (Timmy 2;07;05)

(47) Where's the motor-bike? [You buy the motor-bike]? [That you buy the motorbike]. Where's [you buy that one], where's [you buy that one the motorbike]?"

(Timmy 2;07;03)

Crosslinguistically, these characteristic features have emerged in the early monolingual development of children in a number of different languages, such as French (Hudelot, 1980; Jisa \& Kern, 1998), German (Brandt, Diessel, \& Tomasello, 2006), Hebrew (Dasinger \& Toupin, 1994), and Indonesian (Cole, Hermon, \& Tjung, in press; Hermon, 2005).

These findings indicate that early RCs might be simpler than we thought (Diessel \& Tomasello, 2000, 2005). The classical examples in discussions of adult grammar, such as our hypothetical example (4), involve a RC embedded within a main clause. Examples of this kind are also widely used in experiments on children. In early child language, however, such a complex configuration rarely arises. This is especially true in the case of early object relatives in data like Alicia's utterance in (43), with NPs that have the SVO structure of a main clause.

The isolated nature of early RCs resolves certain problems involved in the processing of prenominal relatives, as discussed in the section on prenominal RCs. In particular, the logical problem of long CRDs, as in (48), does not arise with these types of isolated NPs:

$$
\text { Constituent Recognition Domain for VP }
$$

Because there is no initial verb, the isolated RC consists merely of a NP:

(49) $[\mathrm{NP}[\mathrm{RC}] \mathrm{N}]$

Another option with a similar effect is to make the object NP the sentence topic:

(50) [NP Timmy take that one], I want. (Sophie $3 ; 03 ; 12$ ) 
Again, with the heavy NP preposed, the problem of a long CRD does not arise (Matthews \& Yeung, 2001). In fact, the VO configuration in (50) was not attested at all in the English of the children of this study, although it did arise occasionally in their Cantonese, as in (51):

\author{
(51) Ngo5 zung1ji3 [Siti zing2 go2 di1 McDonald] aa3 (Alicia 2;01;09) \\ I like Siti make DEM CL McDonald SFP \\ "I like the McDonald's [French fries] that Siti makes."
}

Here the NP modified by the RC is the object of a transitive verb, and the problem of a long CRD does arise. However, no such examples were attested in the bilingual children's English. A relevant factor here might be avoidance (Schachter, 1974): The children used various strategies to avoid the [V [Rel $\mathrm{N}]$ ] configuration. Consider the example in (52):

\title{
Daddy, I want ice-cream. [NP Carmen eat that one]. (Sophie 4;01;11)
}

If this were expressed as a single sentence, it would read "I want Carmen eat that one ice-cream," incurring exactly the configuration with a long CRD, as shown in (48). By appending the RC as an afterthought, as in (52), Sophie neatly avoided this configuration. ${ }^{14}$

\section{Attributive Clauses and the NPAH}

We have seen that RCs in East Asian languages such as Cantonese can be analyzed as instances of a more general attributive construction that involves a semantic or pragmatic association rather than a strict grammatical relationship between the head noun and the predicate. One might ask whether the $\mathrm{NPAH}$, initially intended to account for prototypical RCs, should apply to the Cantonese attributive clauses observed in this study. An initial reason to assume that the NPAH can apply to Cantonese attributive clauses is that Keenan and Comrie's (1977) notion of accessibility was not limited to RCs but was argued to be applicable to other domains, including causative and passive constructions: "The Accessibility Hierarchy may play a more general role in determining the accessibility of noun phrases as candidates and targets for syntactic processes" (Keenan \& Comrie, 1977, p. 96). Whether we expect the accessibility hierarchy to apply to attributive clauses depends on what underlies the hierarchy. We assume, following Hawkins (1994, 2004), that accessibility is essentially determined by considerations of sentence processing. Attributive clauses pose challenges similar to those posed by conventional $\mathrm{RCs}$ in terms of processing (although if we pursue Comrie's [1998a, 1998b] suggestion that attributive clauses lack gaps, this would eliminate the need for filler-gap dependency processing). To the extent that this is the case, the accessibility hierarchy that results from processing attributive clauses should be the same as that which results from processing RCs. At the same time, it is not surprising that the processing motivation underlying the accessibility hier- 
archy can be counteracted by other processing factors, such as the isomorphism between main clause structure and object relatives in Cantonese.

\section{CONCLUSIONS}

We have seen that in three Cantonese-dominant bilingual children, prenominal relatives are transferred from Cantonese to English, with object relatives emerging before subject relatives. This is surprising in two respects. First, prenominal relatives are transferred despite being a typologically dispreferred option, especially in a SVO language. Second, the early emergence of object relatives is contrary to the predictions of the NPAH, thereby constituting a potential challenge to a putative language universal.

A partial solution to the puzzle of prenominal relatives is that the earliest RCs are isolated NPs in the sense of Diessel and Tomasello (2000, 2005). Therefore, the processing problems that make prenominal relatives universally dispreferred do not arise. The emergence of object relatives before subject relatives is facilitated by the isomorphism between object relatives and main clauses: The canonical word order strategy might be used by bilingual children as it is used by monolingual children (Tavakolian, 1981). The early object relatives produced by our bilingual children are therefore essentially NPs with the word order of a main clause, resulting in a configuration that is conducive to early production.

We have also explored the possibility that the bilingual children's prenominal object relatives are in fact IHRCs that internally have the syntax of a clause but externally have the syntax of a NP. Under the IHRC analysis, no gap needs to be assumed because the structure of the RC is that of a SVO main clause. Although such an analysis is problematic when applied to adult Cantonese, there would seem to be nothing to prevent children from applying it to their early object relatives.

Another relevant typological insight is that RCs in many East Asian languages are attributive clauses (i.e., a subset of attributive constructions; Comrie, 1996). This characteristic is reflected developmentally in the occurrence of noun-modifying clauses without a grammatical relation to the children's two languages. It would be possible to exclude the apparent counterexample to the NPAH by excluding the Chinese-type relatives as not being true RCs, but this seems to be an essentially terminological solution. We see the NPAH as ultimately driven by processing factors (Hawkins, 1999, 2004). If this is so, it can naturally be overridden by other factors that impinge on processing, such as the isomorphism between the main clause and object relatives in Cantonese.

\section{NOTES}

1. Cantonese examples are given in the Jyut6Ping3 romanization system, developed by the Linguistic Society of Hong Kong (see Tang, Fan, Lee, Lun, Luke, et al., 2002) to meet both linguistic criteria and the constraints imposed by computer applications, which rule out diacritics as used in the Yale system. The IPA and Yale correspondences are given in Matthews and Yip (1994). The numbers at the end of each syllable represent the tone. The abbreviations used in the glosses of the 
language examples are as follows: ACc, accusative case; AUX, auxiliary; CL, classifier; comP, complementizer; DEC, declarative; DEM, demonstrative; REL-PAST, relative past; SFP, sentence final particle; TOP, topic marker. The age specification a;bb;cc represents the age of the child in years, months, and days. Thus (Timmy 2;08;25) indicates that Timmy was at age 2 years, 8 months, and 25 days when the example was recorded.

2. Questions of the form [NP le1/ne1?] in Cantonese (corresponding to [NP ne?] in Mandarin) conventionally mean either "what about x?" or "where's x?" (Matthews \& Yip, 1994).

3. We thank Salikoko Mufwene and an anonymous SSLA reviewer for raising the important issue of the relationship between typological universals and language acquisition.

4. If a determiner appears before the head noun, it will provide a somewhat earlier cue that a NP is being parsed. In the Cantonese RCs at issue here, a determiner and a classifier come immediately before the head noun.

5. This view is somewhat problematic in the case of object relatives in Chinese, in which null objects must be identified with a referent present in the context. Example (a) illustrates the typical use of null objects in Cantonese discourse:

(a) Mother: lo2 violin ceot1 lai4 zou6 mat1je5?

take violin out come do what

"What are you getting the violin out for?"

Child: lo2 ceot1 lai4 taan4 lo1!

take out come play SFP

"I'm taking [it] out to play [it], of course!" (Timmy 2;04;08)

In the child's response, the reference of the missing object is supplied by the noun violin in the mother's utterance. In an object relative such as (b), in contrast, no such contextual referent is present:

(b) Po4po2 maai5 dil tong4-tong2 ne1? (Timmy 2;07;12)

Grandma buy CL candy-candy SFP

"What about the candies Grandma bought?"

The analysis for discourse-bound null objects as in (a) would therefore not be readily applicable to object relatives as in (b). Parallel questions arise concerning gaps in positions other than that of direct object-whether gaps need to be assumed at all and, if so, whether they can be subsumed under null anaphora. Data on the online processing of RCs would help to resolve the question of whether and where filler-gap dependencies are involved (as argued, for example, by Lin et al., 2005).

6. A more elaborate analysis (Cole, 1987), also consistent with the Cantonese data, assumes an anaphoric head following the clause, coreferential with the noun saam1 "clothes" and represented by $e$ in $(\mathrm{a})$ :

(a) $\left[\mathrm{S} / \mathrm{NP} \quad\right.$ Ngo5 zunglji3 go2 dil saam $\left.1_{\mathrm{i}}\right] e_{\mathrm{i}}$ hou2 gwai3

I like DEM CL clothes very expensive

"The clothes I like are expensive."

7. The Hong Kong Bilingual Child Language Corpus can be downloaded from http:// childes.psy.cmu.edu/data/Biling/yipmatthews.zip

8. The possibility remains that contact with other bilingual children might play some role because the three siblings attended kindergarten with children from a variety of language backgrounds. However, the consistency among the three children makes it unlikely that such influences are responsible.

9. The calculation of MLU in words depends on decisions regarding what constitutes a word-a problem that has not been resolved either in general (see Dixon \& Aikhenvald, 2002) or specifically with regard to Chinese (see Packard, 2000). In particular, the concepts of phonological word, morphological word, and syntactic word do not necessarily match. Our calculations of MLU in words are based on the word divisions as they are made in the transcripts of the Hong Kong Bilingual Child Language Corpus. The transcription, in turn, follows the description of Cantonese grammar by Matthews and Yip (1994), except that (for consistency with the CHAT format) the hyphen notation is not used to show word-internal divisions.

10. For ease of exposition, the bracketing shown assumes, by default, the conventional analysis of the children's RCs as head-final relatives. Under the head-internal analysis, the S node that indicates a clausal modifier would not be assumed and the whole NP would have the dual status of $\mathrm{NP} / \mathrm{S}$, as shown in (11). 
11. In the examples elicited by McKee et al. (1998), the nouns "strawberries" in (33) and "bicycle" in (34) indicate the target head nouns of the RCs.

12. The discrepancy in the results for Mandarin might reflect the different materials used: Hsiao and Gibson (2003) used both singly and doubly embedded RCs, whereas Lin et al. (2005) focused on possessor relatives, a category in which there appears to be an advantage for subject relatives.

13. Relative clauses containing a double-object construction, as in (43), are distinct from main clauses in adult but not child Cantonese. In adult Cantonese, the main clause word order would be [give-theme-recipient], whereas the RC order would be [[give-recipient] theme]. This is one piece of evidence against assuming a head-internal analysis of object relatives for adult Cantonese (Matthews \& Yip, 2002). However, in children, and especially in bilingual children's Cantonese, the order [give-recipient-theme] is commonly found (Chan, 2003; Yip \& Matthews, 2007). Consequently, (a) the main clause and RC orders in dative constructions would be nondistinct for our children and (b) this piece of evidence against the head-internal analysis would not be available to our children.

14. The example is transcribed in the diary as two separate utterances, as opposed to a single sentence with the RC [NP Carmen eat that one] as a postmodifier or in dislocated position.

\section{REFERENCES}

Bever, T. G. (1970). The cognitive bases for linguistic structures. In J. R. Hayes (Ed.), Cognition and development of language (pp. 279-362). New York: Wiley.

Brandt, S., Diessel, H., \& Tomasello, M. (2006). The acquisition of German relative clauses: A case study. Manuscript submitted for publication.

Chan, A. W.-S. (2003). The development of bei2 dative constructions in early child Cantonese. Unpublished master's thesis, Chinese University of Hong Kong.

Cole, P. (1987). The structure of internally headed relative clauses. Natural Language and Linguistic Theory, 5, 277-302.

Cole, P., Hermon, G., \& Tjung, Y. N. (in press). The formation of relative clauses in Jakarta Indonesian. In A. van Engelenhoven \& H. Steinhauser (Eds.), Selected studies on Indonesian/Malay linguistics. Kuala Lumpur: Dewan Bahasa dan Pustaka; Leiden: International Institute for Asian Studies.

Comrie, B. (1996). The unity of noun-modifying clauses in Asian languages. In Pan-Asiatic Linguistics: Proceedings of the Fourth International Symposium on Languages and Linguistics, January 8-10, 1996 (pp. 1077-1088). Salaya, Thailand: Institute of Language and Culture for Rural Development, Mahidol Univeristy at Salaya.

Comrie, B. (1998a). Rethinking the typology of relative clauses. Language Design, 1, 59-86.

Comrie, B. (1998b). Attributive clauses in Asian languages: Towards an areal typology. In W. Boeder, C. Schroeder, K. Wagner, \& W. Wildgen (Eds.), Sprache in Raum und Zeit: In memoriam Johannes Bechert, Band 2 (pp. 51-60). Tübingen: Gunter Narr.

Comrie, B. (2002). Typology and language acquisition: The case of relative clauses. In A. Giacalone Ramat (Ed.), Typology and second language acquisition (pp. 19-37). Berlin: Mouton de Gruyter.

Dasinger, L., \& Toupin, C. (1994). The development of relative clause functions in narratives. In R. Berman \& D. Slobin (Eds.), Relating events in narrative: A cross-linguistic developmental study (pp. 457-514). Mahwah, NJ: Erlbaum.

Diessel, H., \& Tomasello, M. (2000). The development of relative clauses in English. Cognitive Linguistics, 11, 131-151.

Diessel, H., \& Tomasello, M. (2005). A new look at the acquisition of relative clauses. Language, 81, 882-906.

Dixon, R. W., \& Aikhenvald, A. Y. (Eds.). (2002). Word: A cross-linguistic typology. New York: Cambridge University Press.

Döpke, S. (1998). Competing language structures: The acquisition of verb placement by bilingual German-English children. Journal of Child Language, 25, 555-584.

Dryer, M. (1992). The Greenbergian word order correlations. Language, 68, 81-138.

Gass, S., \& Ard, J. (1984). Second language acquisition and the ontology of language universals. In W. Rutherford (Ed.), Language universals and second language acquisition (pp. 33-68). Amsterdam: Benjamins.

Genesee, F., Nicoladis, E., \& Paradis, J. (1995). Language differentiation in early bilingual development. Journal of Child Language, 22, 611-631.

Gibson, E. (1998). Linguistic complexity: Locality of syntactic dependencies. Cognition, 69, 1-76.

Hawkins, J. A. (1987). Implicational universals as predictors of language acquisition. Linguistics, 25, 453-473.

Hawkins, J. A. (1990). A parsing theory of word order universals. Linguistic Inquiry, 21, 223-262. 
Hawkins, J. A. (1994). A performance theory of order and constituency. New York: Cambridge University Press.

Hawkins, J. A. (1999). Processing complexity and filler-gap dependencies across grammars. Language, 75, 244-285.

Hawkins, J. A. (2004). Efficiency and complexity in grammars. Oxford: Oxford University Press.

Hermon, G. (2005, June). The acquisition of relative clauses in colloquial Jakarta Indonesian. Paper presented at the Workshop on the Typology, Processing and Acquisition of Relative Clauses, Max Plank Institute for Evolutionary Anthropology, Leipzig, Germany.

Hsiao, F., \& Gibson, E. (2003). Processing relative clauses in Chinese. Cognition, 90, 3-27.

Hudelot, C. (1980). Qu'est-ce que la complexité syntaxique? L'exemple de la relative. [What is syntactic complexity? The case of the relative clause.] La Linguistique, 16, 5-41.

Hyltenstam, K. (1984). The use of typological markedness conditions as predictors in second language acquisition: The case of pronominal copies in relative clauses. In R. Andersen (Ed.), Second languages: A cross-linguistic perspective (pp. 39-58). Rowley, MA: Newbury House.

Jisa, H., \& Kern, S. (1998). Relative clauses in French children's narrative texts. Journal of Child Language, 25, 623-652.

Keenan, E. (1985). Relative clauses. In T. Shopen (Ed.), Language typology and syntactic description: Vol. 2. Complex constructions (pp. 141-170). New York: Cambridge University Press.

Keenan, E., \& Comrie, B. (1977). Noun phrase accessibility and Universal Grammar. Linguistic Inquiry, 8, 63-99.

Lau, E. (2006). The acquisition of relative clause by Cantonese children: An experimental approach. Unpublished master's thesis, University of Hong Kong.

Lin, C., Fong, S., \& Bever, T. (2005). Constructing filler-gap dependencies in Chinese possessor relative clauses. Proceedings of PACLIC 19, the $19^{\text {th }}$ Pacific-Asia Conference on Language, Information and Computation (pp. 143-154). Taipei: Academia Sinica.

MacWhinney, B. (2000). The CHILDES Project: Tools for analyzing talk (3rd ed.). Mahwah, NJ: Erlbaum.

Matthews, S., \& Yeung, L. (2001). Processing motivations for topicalization in Cantonese. In K. Horie \& S. Sato (Eds.), Cognitive-functional linguistics in an East Asian context (pp. 81-102). Tokyo: Kurosio Publishers.

Matthews, S., \& Yip, V. (1994). Cantonese: A comprehensive grammar. London: Routledge.

Matthews, S., \& Yip, V. (2001). The structure and stratification of relative clauses in contemporary Cantonese. In H. Chappell (Ed.), Sinitic grammar: Synchronic and diachronic perspectives (pp. 266281). Oxford: Oxford University Press.

Matthews, S., \& Yip, V. (2002). Relative clauses in early bilingual development: Transfer and universals. In A. Giacalone Ramat (Ed.), Typology and second language acquisition (pp. 39-81). Berlin: Mouton de Gruyter.

McKee, C., McDaniel, D., \& Snedeker, J. (1998). Relative clauses children say. Journal of Psycholinguistic Research, 27, 573-596.

Packard, J. (2000). The morphology of Chinese: A linguistic and cognitive approach. New York: Cambridge University Press.

Paradis, J., \& Genesee, F. (1996). Syntactic acquisition in bilingual children: Autonomous or interdependent? Studies in Second Language Acquisition, 18, 1-25.

Schachter, J. (1974). An error in error analysis. Language Learning, 24, 205-214.

Tang, S.-W., Fan, K., Lee, T., Lun, C., Luke, K.-K., Tung, P., et al. (Eds). (2002). Guide to LSHK Cantonese romanization of Chinese characters (2nd ed.). Hong Kong: Linguistic Society of Hong Kong.

Tarallo, F., \& Myhill, J. (1983). Interference and natural language in second language acquisition. Language Learning, 33, 55-76.

Tavakolian, S. (1981). The conjoined clause analysis of relative clauses. In S. Tavakolian (Ed.), Language acquisition and linguistic theory (pp. 167-87). Cambridge, MA: MIT Press.

Tomlin, R. (1994). Functional grammars, pedagogical grammars, and communicative language teaching. In T. Odlin (Ed.), Perspectives on pedagogical grammar (pp. 140-178). New York: Cambridge University Press.

Yip, V., \& Matthews, S. (1995). I-interlanguage and typology: The case of topic-prominence. In L. Eubank, L. Selinker, \& M. Sharwood Smith (Eds.), The current state of interlanguage: Studies in honor of William Rutherford (pp. 17-30). Amsterdam: Benjamins.

Yip, V., \& Matthews, S. (2000). Syntactic transfer in a Cantonese-English bilingual child. Bilingualism: Language and Cognition, 3, 193-207.

Yip, V., \& Matthews, S. (2006). Assessing language dominance in bilingual acquisition: A case for mean length of utterance differentials. Language Assessment Quarterly, 3, 97-116.

Yip, V., \& Matthews, S. (2007). The bilingual child: Early development and language contact. New York: Cambridge University Press. 